Research Article

\title{
The Stiffness Calculation and Optimization for the Variable Stiffness Load Torque Simulation System
}

\author{
Zhe Ji, Xiaoxian Yao, and Zuobao Liang \\ School of Aerospace Engineering, Beijing Institute of Technology, Beijing 100081, China \\ Correspondence should be addressed to Zuobao Liang; liangzb_bit@126.com
}

Received 2 July 2017; Revised 16 October 2017; Accepted 23 October 2017; Published 5 December 2017

Academic Editor: Mahmut Reyhanoglu

Copyright () 2017 Zhe Ji et al. This is an open access article distributed under the Creative Commons Attribution License, which permits unrestricted use, distribution, and reproduction in any medium, provided the original work is properly cited.

\begin{abstract}
This paper presents a novel design for a variable stiffness load torque simulation system. The system is applied to the load torque on a rudder in a real-time hardware-in-the-loop system (HILS). Compared with the traditional loading method, in which unavoidable additional torque exists, the variable stiffness loading system employs a "first decomposed and then coupled" approach to output the load torque and to significantly reduce the additional torque. Based on experimental data obtained from a wind tunnel test, a calculation method is proposed to determine the loading parameters of the variable stiffness loading system. Since the load stiffness is related to a variety of factors, the stiffness values obtained from wind tunnel test data, such as the fixed Mach number and the rudder deflection angle, are not definite values. By analyzing the influencing factors of the loading parameters, an optimal set of load stiffness is obtained using an optimization algorithm, and exact tracking of the load torque is achieved. Using the calculation method to obtain a loading torque for the rudder as an example, the torque tracking error is less than $0.05 \mathrm{Nm}$. The simulation results indicate that the proposed calculation method for variable stiffness loading is effective.
\end{abstract}

\section{Introduction}

A hinge moment refers to the torque produced by an aerodynamic force acting on the surface of an aircraft at the rudderpost [1-3]. A rudder load torque simulation system is employed to simulate the hinge moment during an aircraft's flight and to assess the realistic workload of a rudder by performing a flight simulation and performance testing of an aircraft under loading conditions [4]. The loading system can be divided into a mechanical loading system, a hydraulic loading system, and an electric loading system according to different load actuators $[5,6]$. The mechanical loading system primarily uses weight, an inertia plate, and a torsion bar spring as the loading media. This type of loading system has a simple structure with fixed stiffness, is reliable, and does not require any additional power; however, it cannot track continuously changing loads. The electrohydraulic loading system uses a hydraulic motor or hydraulic cylinder as an actuator and has the advantages of a fast response, superior dynamic performance, and high precision, with the disadvantages of power dissipation, loud noise, low energy utilization rate, and additional torque $[7,8]$. The traditional electric loading system uses a torque motor, which has a strong small-signal tracking ability, stable performance, and small size. However, this type of system regards the torque as a controlled variable [9-11] and must track the position command of the rudder while tracking the torque command signal. Thus, the presence of additional torque is inevitable [12-14].

The variable stiffness loading mode uses the torsion bar spring as the loading medium and changes the stiffness by adjusting the working length of the torsion bar spring. Because the actual load of the torsion bar spring and the actual load of a rudder during a missile's flight are elastic loads, this loading mode can better simulate the actual load of the rudder. The load mode adopts a "first decomposed and then coupled" approach. With this approach, better dynamic loading accuracy is achieved. Moreover, this approach is a method of indirect loading regarding torque, which presents a technological challenge for a variable stiffness loading simulator in calculating simulation data to obtain the load parameters and to output the torque with two loading parts. This article presents a calculation method for the loading parameters; this method is combined 


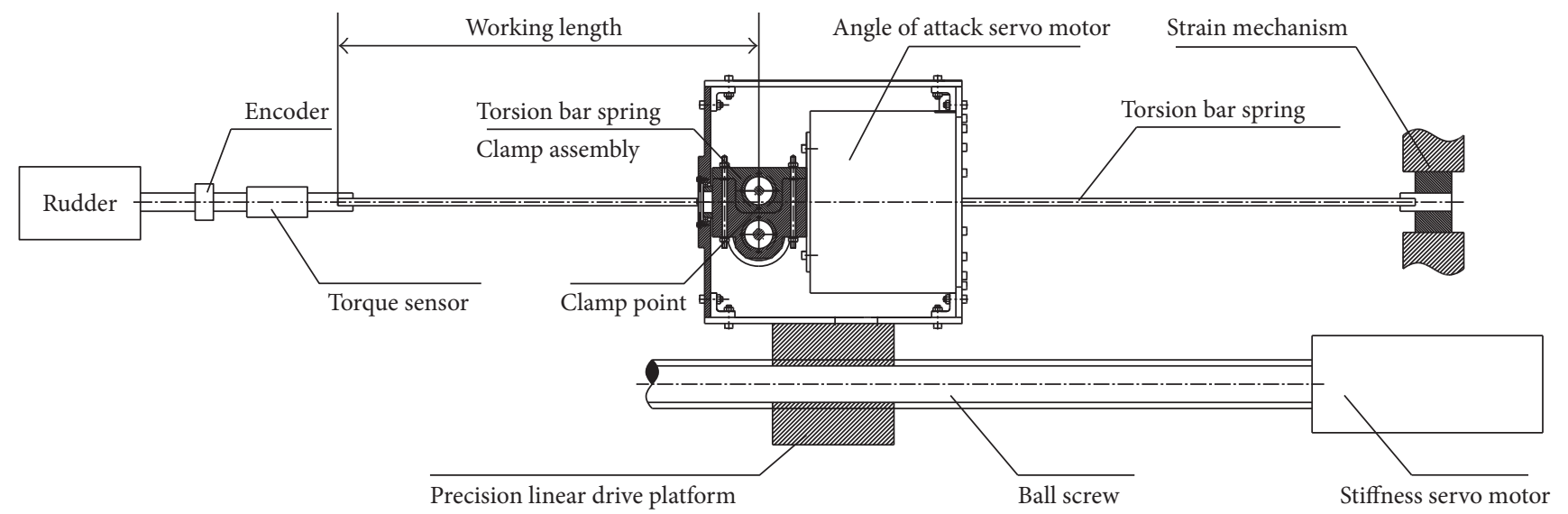

FIGURE 1: Structure of the variable stiffness loading system.

with existing data obtained from a wind tunnel test and obtains a hardware-in-the-loop system (HILS) using an emulation computer.

An optimization method is a mathematical method that examines how to find certain factors with a given constraint and a certain indicator to achieve the optimal effect. Schaffer [15] proposed the use of a genetic algorithm to solve the problem of objective optimization. Rahmati et al. [16] designed a nonlinear objective optimization method to enhance the passive control performance of rubbers by minimizing the destructive effects of shock and random excitations. By analyzing the influence of the initial load stiffness acting on the loading effect, the loading parameters must be optimized to obtain the best working results.

\section{Basic Principle of the Variable Stiffness Loading System}

2.1. Composition of the Variable Stiffness Loading System. As shown in Figure 1, the variable stiffness loading system is composed of a basic platform simulator, a load stiffness servo system, a dynamic angle of attack compensation system, a rudder output shaft connector, and auxiliary components [17].

The loading system adopts a combination of two loading parts: a passive loading part and an active loading part. The former uses a rudder deflection angle. The latter uses a dynamic angle of attack compensation. The load stiffness servo system using a stiffness servo motor adjusts the stiffness via changes in the working length of the torsion bar spring. The active movement of a rudder simulates the rudder deflection load torque (RDLT). One end of the torsion bar spring is connected to the rudder output shaft. When the rudder performs an active movement, a constraint torsion angle is produced, whereas the clamp point of the torsion bar spring is fixed with a movable clamp assembly. The dynamic angle of the attack compensation system using an angle of attack servo motor simulates the nonrudder deflection load torque (NRDLT). The motor outputs an angle to drive the clamp assembly to twist with the clamp point of the torsion bar spring generating the constraint torsion.
The angle of attack servo system adds the NRDLT to the RDLT generated by the torsion of the rudder deflection. The two parts of the torsion angle (the rudder deflection angle and the nonrudder deflection angle) constitute the total torsion angle for generating the target load torque to simulate the load spectrum on the rudder shaft during a missile's flight.

We define the load stiffness $K$ as the torque caused by a unit angle of the torsion bar spring. The relationship between $K$ and the size of its structure is presented as

$$
K=\frac{T}{\theta}=\frac{k a^{3} b G}{L},
$$

where $\theta$ is the twist angle; $T$ is the torque; $k$ is the section factor of the rectangular materials; $L, a$, and $b$ are the working length, thickness, and width, respectively, of the torsion bar spring; and $G$ is the elastic shear modulus.

As demonstrated by formula (1), changing the working length of the torsion bar spring can change the stiffness [18] and enable the load stiffness to change via a set of stiffness servo systems at different flight altitudes and Mach numbers. The dynamic angle of attack compensation mechanism generates torque by outputting a twist angle to track the changes of NRDLT caused by the angle of attack. Therefore, the load stiffness and the equivalent angle of attack are the loading parameters required by the variable stiffness loading system.

2.2. Composition of the Load Torque. The correlations between the hinge moment $M_{\mathrm{h}}$, the rudder deflection angle $\delta$, and the angle of attack $\alpha$ are [19]

$$
M_{\mathrm{h}}=M_{\mathrm{h}}^{\alpha} \alpha+M_{\mathrm{h}}^{\delta} \delta
$$

where $M_{\mathrm{h}}^{\alpha}$ and $M_{\mathrm{h}}^{\delta}$ refer to the torque gradients of the angle of attack and the rudder deflection angle, respectively. These values are related to parameters such as the flight altitude and Mach number.

As expressed by formula (2), the load torque consists of two parts: the slow-changing $\alpha$-dependent load torque $M_{\mathrm{h}}^{\alpha} \alpha$ caused by the angle of attack $\alpha$ and the deflection- 
dependent load torque $M_{\mathrm{h}}^{\delta} \delta$ related to the characteristics of the rudder.

To facilitate the realization of loading, we consider $M_{\mathrm{h}}^{\alpha}$ to equal $M_{\mathrm{h}}^{\delta}$, both of which are referred to as the load stiffness and are denoted by $K . K$ is related to the flight Mach number and altitude as follows:

$$
K=M_{\mathrm{h}}^{\delta}
$$

According to the characteristics of the torque during the flight process of a missile, as shown in formula (2), the variable stiffness load torque simulation system divides the torque into two parts. During the missile's flight, the load stiffness will change according to variations in the Mach number, altitude, and other parameters [20]. Thus, the change rate of the load stiffness is relatively slow. The changing frequency of the angle of attack is limited, whereas the change in rudder deflection varies significantly for different types of rudders. For example, the dynamic frequency is generally on the order of $10 \mathrm{~Hz}$ for nonspinning missile rudders, whereas spinning missile rudders have a higher requirement for dynamic frequency. Therefore, the load torque for the rudder during a missile's flight consists of two parts: the RDLT related to the characteristics of a rudder and the NRDLT with relatively slow changes.

The load torque provided by the torsion bar spring is a passive torque associated with the rudder deflection angle. The active movement of the rudder is not a coupling disturbance of the load torque but is rather a part of the load torque. The torsion bar spring has a very high intrinsic frequency; thus, the system can effectively reduce the additional torque of the conventional loading device. By outputting the compensation angle of attack from a torque motor, the system outputs the compensation torque based on the load torque caused by the active movement of the rudder deflection angle, which improves the dynamic loading accuracy and the response bandwidth of the rudder load.

\subsection{Realization of the Angle of Attack Compensation. $M_{\mathrm{h}}^{\alpha}$} differs from $M_{\mathrm{h}}^{\delta}$. In formula (2), by introducing the load stiffness $K=M_{\mathrm{h}}^{\delta}$, if the hinge moment remains unchanged, the angle of attack $\alpha$ must be converted into the equivalent angle of attack $\alpha^{\prime}$, which is obtained from formula (4).

$$
\alpha^{\prime}=\frac{M_{\mathrm{h}}^{\alpha} \alpha}{M_{\mathrm{h}}^{\delta}}=\frac{M_{\mathrm{h}}-K \delta}{K} .
$$

Since the torque of the torsion bar spring is proportional to the twist angle, it can output the equivalent angle of attack by the part of the angle of attack servo system working on the torsion bar spring. This torque is the NRDLT. Due to the limited variation of the angle of attack's frequency and amplitude during an actual flight, the frequency and amplitude of the equivalent angle of attack after conversion are usually small.

\section{Calculation Principle for Loading Parameters}

The traditional electric loading method, which regards the torque as a controlled variable, obtains the real-time load torque by receiving an interpolation of discrete data points from an emulation computer using an HILS. The load torque simulation system needs to track the torque command while tracking the rudder deflection angle. Therefore, this coupling system will produce additional torque, which affects the load accuracy and response bandwidth.

By introducing the load stiffness, this article divides the load torque into two parts. The key issue is that the loading parameters obtained by calculating the real-time load torque are associated with the Mach number, the flight altitude, and other factors. The calculation principle using the wind tunnel test data is presented as follows:

(i) For the condition of a fixed Mach number, the load torque corresponding to the value of each attack angle (i.e., the NRDLT caused by the angle of attack) is taken as the offset at the $0^{\circ}$ rudder deflection angle, which is denoted as $M_{\mathrm{h} 0}$.

(ii) For the Mach number condition in step (i), the load torque is $M_{\mathrm{h}}=M_{\mathrm{h} 0}+M_{\mathrm{h}}^{\delta} \delta$ when the rudder deflection angle is not $0^{\circ}$. This equation demonstrates that the hinge moment $M_{\mathrm{h}}$ is divided into the NRDLT $M_{\mathrm{h} 0}$ and the RDLT $M_{\mathrm{h}}^{\delta} \delta$, where the RDLT has a linear correlation with the rudder deflection angle $\delta$.

(iii) The linearized theory is formulated as

$$
\begin{aligned}
\Delta M_{\mathrm{h}} & =M_{\mathrm{h}(i+1)}-M_{\mathrm{h}(i)} \\
& =\left(M_{\mathrm{h}}^{\delta} \delta_{(i+1)}+M_{\mathrm{h} 0}\right)-\left(M_{\mathrm{h}}^{\delta} \delta_{i}+M_{\mathrm{h} 0}\right) \\
& =M_{\mathrm{h}}^{\delta}\left(\delta_{(i+1)}-\delta_{i}\right) \\
& =M_{\mathrm{h}}^{\delta} \cdot \Delta \delta,
\end{aligned}
$$

where $M_{\mathrm{h}(i+1)}$ and $M_{\mathrm{h}(i)}$ are the load torque values when the Mach number and the angle of attack are equivalent and the rudder deflection angles differ.

Thus, the torque gradient of the rudder deflection angle $M_{\mathrm{h}}^{\delta}=\Delta M_{\mathrm{h}} / \Delta \delta$ is obtained; that is, one of the load parameters, the load stiffness $K=M_{\mathrm{h}}^{\delta}$, is obtained.

With the gradient $M_{\mathrm{h}}^{\delta}$ and the nondimensional hinge moment coefficient $m_{\mathrm{h}}^{\delta}$, the following formula is presented:

$$
M_{\mathrm{h}}^{\delta}=\frac{1}{2} m_{\mathrm{h}}^{\delta} \rho_{0} V^{2} S_{\text {ref }} b_{\mathrm{A}},
$$

where $\rho_{0}=1.225 \mathrm{~kg} / \mathrm{m}^{3}, V$ is the flight speed, $S_{\text {ref }}$ is the reference area of the control surface, and $b_{\mathrm{A}}$ is the average aerodynamic chord of the control surface. 
Because the air density will change in accordance with altitude during actual flight,

$$
\rho=\rho_{0}\left(\frac{T}{T_{0}}\right)^{4.256},
$$

where $T=T_{0}-0.0065 \mathrm{H}$ and $T_{0}=288.15 \mathrm{~K}$.

Since the data obtained from the wind tunnel test do not consider the impact of the flight altitude $H$ (air density is constant) or the impact of the altitude on stiffness, a correction coefficient $\mu$ is needed to add to the obtained stiffness using the wind tunnel test data:

$$
\mu=\frac{\rho}{\rho_{0}},
$$

and the corrected load stiffness is

$$
K^{*}=\mu M_{\mathrm{h}}^{\delta}
$$

(iv) The angle of attack value required by the hinge moment $M_{\mathrm{h} 0}$ is converted to the equivalent angle of attack $\alpha^{\prime}$, which is defined as $\alpha^{\prime}=M_{\mathrm{h} 0} / K^{*}$.

According to the working principle of the variable stiffness load simulator, the purpose of this solution is to obtain the loading parameters, the load stiffness $K$, and the equivalent angle of attack $\alpha^{\prime}$, at each sampling time.

\section{Implementation of the Loading Process}

In the process of variable stiffness loading, two steps need to be conducted: first, reasonable loading parameters (including the load stiffness and the equivalent angle of attack) must be obtained based on existing wind tunnel test data; second, the resulting loading parameters must be reasonably applied to the loading device to obtain the desired loading effects.

4.1. Solution Method. The concept of variable stiffness loading is summarized as follows: during the process of loading, the load stiffness changes in accordance with variations in the Mach number and altitude. The change in the working length of the torsion bar spring primarily depends on the changes in the Mach number and altitude. The angle of attack converted under the load stiffness is referred to as the equivalent angle of attack. The target load torque is determined by the spring's torsion angle, which consists of the equivalent angle of attack and the rudder deflection angle.

The loading process is explained as follows:

(i) The existing wind tunnel test data are processed, and the load stiffness $K$ for the tested Mach number is obtained.

(ii) The real-time data (including the Mach number, altitude, rudder deflection angle, angle of attack, and corresponding load torque) are read from the emulation computer.

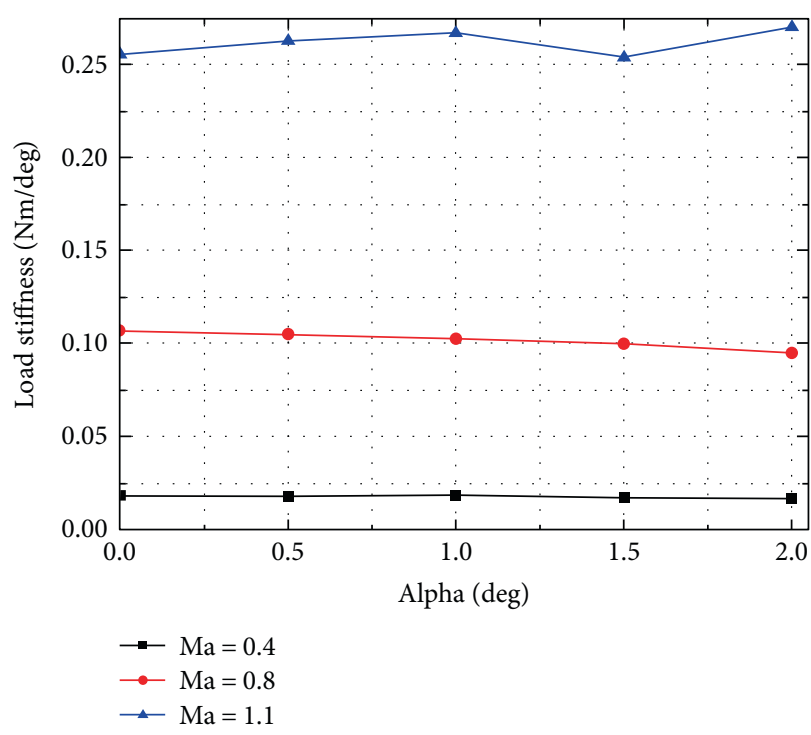

Figure 2: Changing curve line of the load stiffness.

(iii) The load stiffness for the current Mach number is calculated by interpolation, and the correction coefficient $\mu$ is introduced to consider the impact of altitude on the load stiffness. Thus, the real-time load stiffness $K^{*}$ for the current flight condition is obtained. The stiffness servo system tracks the calculated load stiffness in real time by changing the working length of the torsion bar spring. The active movement of the rudder deflection drives the deformation of the torsion bar spring to generate RDLT with the load stiffness.

(iv) The target load torque $M_{\mathrm{h}}$ and the load stiffness $K^{*}$ obtained from step (iii) are used to calculate the real-time NRDLT $M_{\mathrm{h}}^{0}$, and the equivalent angle of attack $\alpha^{\prime}$ at the moment is calculated. The dynamic angle of the attack servo system drives the deformation of the torsion bar spring via torque motor tracking of the equivalent angle of attack to output the NRDLT. At the point of the load stiffness, the rudder deflection angle causes deformation by twisting the spring. Based on the deformation, the torque motor tracks the superposition of the equivalent angle of the attack outputting the spring torsion angle, which is a combination action to output the target load torque.

4.2. Solution Examples. As shown in Figure 2, the curve line of the load stiffness, which corresponds to changes in the Mach number and angle of attack, is obtained by applying the wind tunnel test data in accordance with the proposed method.

The change in the angle of attack does not affect the load stiffness within a range of small angles. The set of load stiffness calculated using the wind tunnel test data for a set of fixed Mach numbers is shown in Table 1. The load stiffness for other Mach numbers is obtained during flight by interpolation. 
TABLE 1: Load stiffness for fixed Mach numbers.

\begin{tabular}{lccc}
\hline Mach number & 0.4 & 0.8 & 1.1 \\
\hline Load stiffness & $k_{1}$ & $k_{2}$ & $k_{3}$ \\
$K^{*}\left(\mathrm{Nm} /^{\circ}\right)$ & 0.02 & 0.100 & 0.253 \\
Value &
\end{tabular}

The emulation computer is given the following signals:

(i) The angle of attack signal is a sinusoidal signal with an amplitude of $0 \sim 2^{\circ}$ and a frequency of $0.8 \mathrm{~Hz}$.

(ii) The Mach number signal is a ramp signal of $0.4 \sim 1.1 \mathrm{Ma}$ from $0 \sim 4 \mathrm{~s}$, remaining at $1.1 \mathrm{Ma}$ from 4 to $8 \mathrm{~s}$.

(iii) Simulation time is $8 \mathrm{~s}$.

The rudder deflection angle signal uses a Schroederphased harmonic signal (SPHS), which was proposed by Schroeder [21] and is superposed by several amplitude values, periods, and cosine waves related to the initial phase. The composition of the initial phase angle of the signals' cosine components is adjusted to form periodic multifrequency signals with unique characteristics, with a general mathematical expression of

$$
u(t)=\sum_{k=1}^{\mathrm{NH}} a_{k} \cos \left(\frac{2 \pi k}{T_{\mathrm{p}}}+\theta_{k}\right),
$$

where $\mathrm{NH}$ is the harmonic number of the signals, $a_{k}$ is the amplitude of the $k$ th harmonic wave, $\theta_{k}$ is the initial phase of the $k$ th harmonic wave, and $T_{\mathrm{p}}$ is the period of the signal fundamental wave. In practical applications, $a_{1}=$ $a_{2}=\cdots=a_{k}=$ const is usually adopted; thus, the following form is given:

$$
\begin{aligned}
u(t) & =\sum_{k=1}^{\mathrm{NH}} \sqrt{\frac{2}{\mathrm{NH}}} \cos \left(\frac{2 \pi k}{T_{\mathrm{p}}}+\theta_{k}\right), \\
\theta_{k} & =\frac{2 \pi}{\mathrm{NH}} \sum_{i=1}^{k} i .
\end{aligned}
$$

This article adopts a rudder deflection angle signal with $\mathrm{NH}=20$ and $T_{\mathrm{p}}=4$, and

$$
\delta(t)= \begin{cases}0.5 \operatorname{SPHS}\left(\mathrm{NH}, T_{\mathrm{p}}\right)-0.5 & t<2 s . \\ 2.5 \operatorname{SPHS}\left(\mathrm{NH}, T_{\mathrm{p}}\right)+1 & 2 s \leq t<5 s . \\ 0.5 \operatorname{SPHS}\left(\mathrm{NH}, T_{\mathrm{p}}\right)+3 & 5 s \leq t<8 s .\end{cases}
$$

The input signal curves are shown in Figure 3.

The required load stiffness curve during the loading process is shown in Figure 4.

As shown in Figure 4, the load stiffness is acquired by interpolation according to the discrete data listed in Table 1. The variation in load stiffness changes slowly because the Mach number does not significantly change.
The curve line of the equivalent angle of attack $\alpha^{\prime}$ is calculated according to formula (4), as shown in Figure 5. The variations in frequency and amplitude are both small; thus, the angle of attack servo system can adequately track the equivalent angle of attack.

A comparison between the command load torque and the actual load torque is shown in Figure 6.

In Figure 6(a), the command load torque is the torque command sent by the emulation computer in real time, calculated by wind tunnel test data interpolation. The actual load torque is obtained from the combined action of the equivalent angle of attack and the real-time rudder deflection angle at the calculated real-time load stiffness point according to the method proposed in this article. Based on the method proposed in this article, Figure 6(b) shows that the variable stiffness loading system can adequately track the load torque, with a maximum tracking error of $0.05 \mathrm{Nm}$.

\section{Optimization of the Load Stiffness}

As shown in Figure 2, the load stiffness is not a constant value for the condition in which the Mach number and the rudder deflection angle are fixed but varies slightly with changes in the angle of attack. We obtained only a few discrete data points of finite numbers from the wind tunnel test. The load torque obtained by interpolating the discrete data points obtained from the wind tunnel test data is $M_{1}(t)$, and the real-time load stiffness and the equivalent angle of attack are obtained by the method described in Section 3. The actual load torque is indirectly obtained at $M_{2}(t)$; that is,

$$
M_{2}(t)=K(t)\left[\delta(t)+\alpha^{\prime}(t)\right]
$$

where $M_{1}(t)$ and $\delta(t)$ are the real-time inputs of the loading system, which are obtained by the emulation computer and $K(t)$ and $\alpha^{\prime}(t)$ are the actual outputs of the stiffness servo system and the angle of attack servo system, respectively.

The load stiffness values are obtained $\left(K^{*}=0.02,0.1\right.$, $0.253)$ for fixed Mach numbers $(\mathrm{Ma}=0.4,0.8,1.1)$, as shown in Table 1. For a given Mach number, the actual load torque is calculated with different sets of load stiffness for the initial value. Compared with the command torque, the torque tracking error is used to evaluate the tracking effect. The tracking error is denoted as $e=M_{1}-M_{2}$. The root mean square error of the tracking load torque $J_{\mathrm{fit}}$ is used as an evaluation parameter for the torque tracking effect, which is referred to as

$$
J_{\mathrm{fit}}=\min \sqrt{\frac{1}{n} \sum_{i=1}^{n} e(i) \cdot e^{T}(i)},
$$

where $n$ is the length of the torque tracking error sequence.

As reflected by the data in Table 2, the different sets of load stiffness for a fixed Mach number have a certain effect on the tracking of the loading torque. This result occurs because the stiffness solution is based on the Mach number value interpolation, and the discrete data points in the wind tunnel test data are used as the weight of the load stiffness for other arbitrary Mach number conditions. Hence, there 

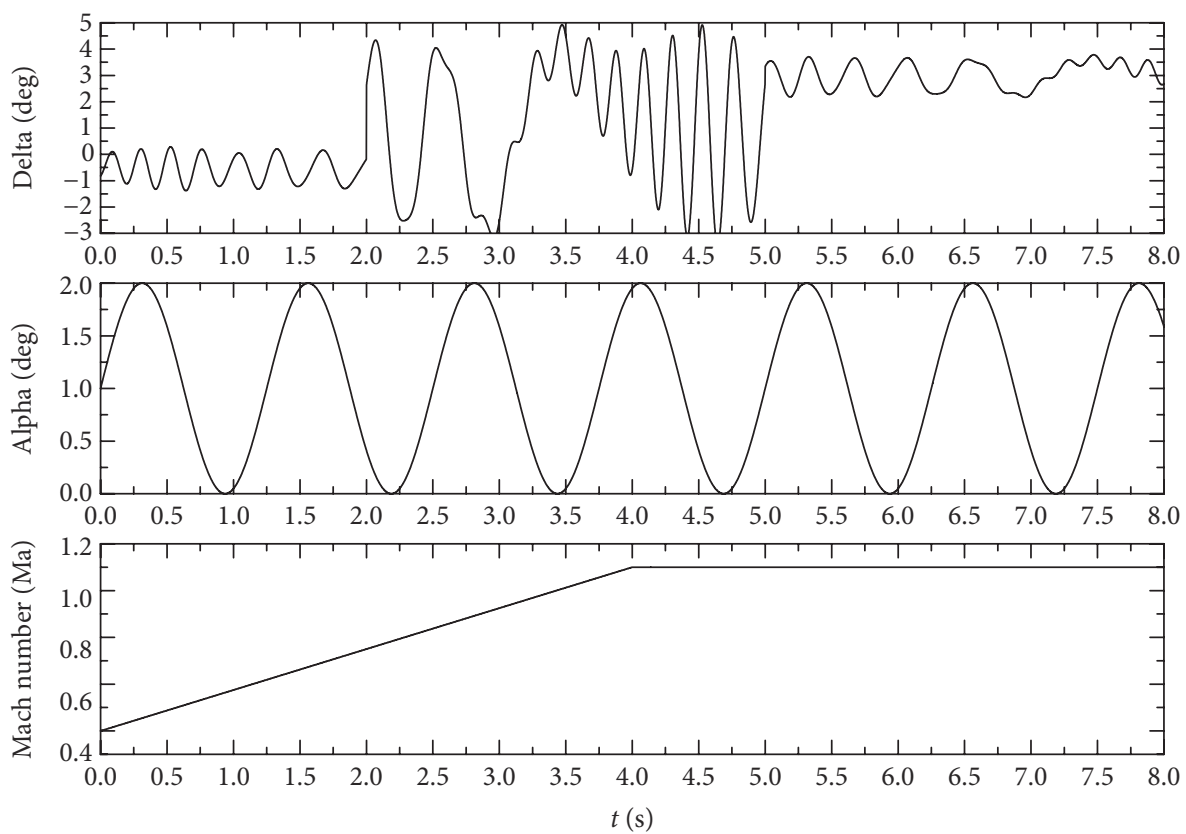

FIgURe 3: Input signals.

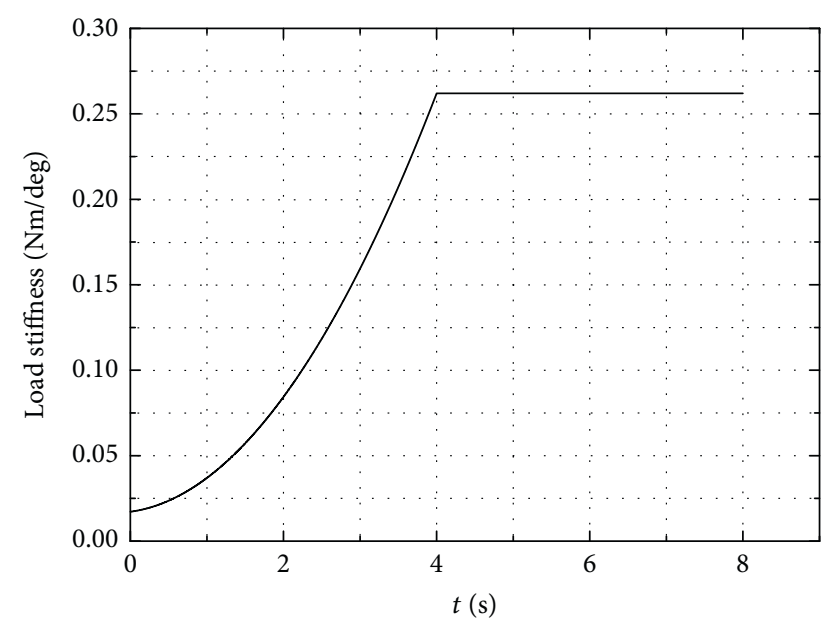

Figure 4: Load stiffness.

must be a set of optimal load stiffness for fixed Mach values, causing the root mean square error of the load torque variance to reach a minimum. In this article, a genetic algorithm is used to train the wind tunnel test data to readjust the stiffness value obtained for a fixed Mach number. Objective optimization is used to obtain the optimal set of load stiffness.

We select an independent variable $x=\left(k_{1}, k_{2}, k_{3}\right)$, where formula (14) acts as an objective function. The bounds for the objective functions are given.

$$
\begin{gathered}
0.01 \leq k_{1} \leq 0.025, \\
0.05 \leq k_{2} \leq 0.2, \\
0.21 \leq k_{3} \leq 0.4 .
\end{gathered}
$$

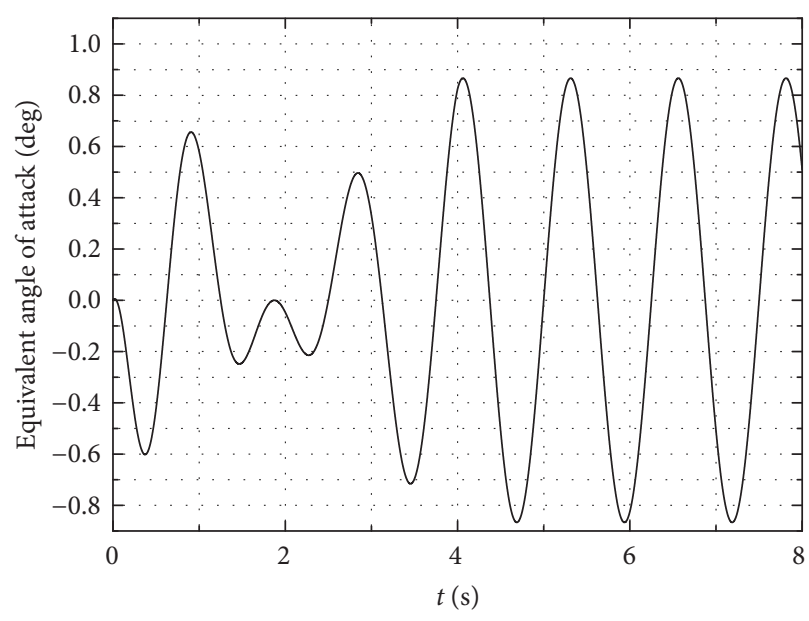

FIgURe 5: Equivalent angle of attack.

The optimal result is obtained by the optimization calculation, and the minimum value of $J_{\text {fit }}$ is obtained, as shown in Table 3.

\section{Conclusion}

This article proposes a load stiffness solving method based on a variable stiffness rudder simulation loading system and optimizes the design of the discrete load stiffness data points obtained from wind tunnel test data. The conclusions are as follows:

(i) The variable stiffness rudder simulation loading system can divide the load torque into the RDLT and the NRDLT with the torsion bar spring as the loading medium. Two load parameters are obtained 


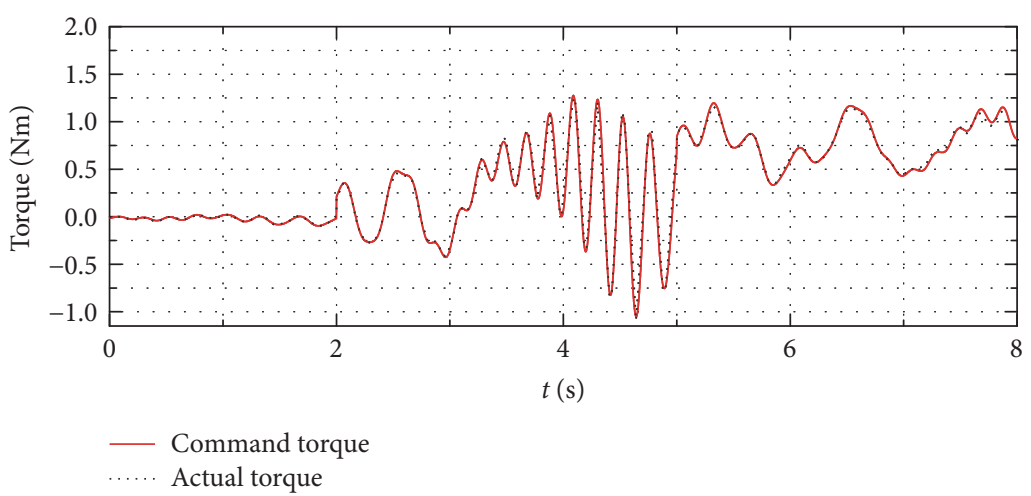

(a)

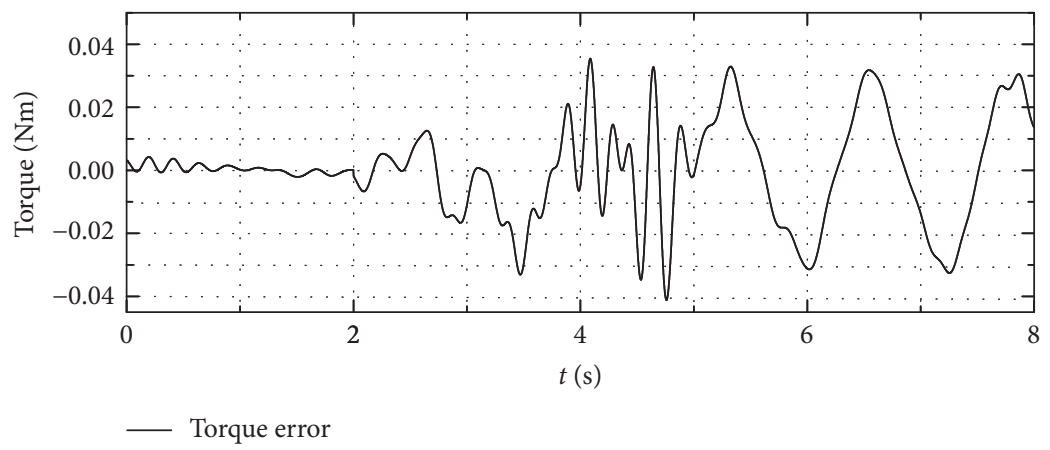

(b)

Figure 6: Comparison between the command load torque and the actual load torque.

TABLE 2: Root mean square error for different load stiffness values.

\begin{tabular}{lcccc}
\hline $\begin{array}{l}\text { Data } \\
\text { group }\end{array}$ & $\begin{array}{c}\mathrm{Ma}=0.4 \\
\text { Load stiffness } \\
\left(\mathrm{Nm} /{ }^{\circ}\right) \\
k_{1}\end{array}$ & $\begin{array}{c}\mathrm{Ma}=0.8 \\
\text { Load stiffness } \\
\left(\mathrm{Nm} /{ }^{\circ}\right) \\
k_{2}\end{array}$ & $\begin{array}{c}\mathrm{Ma}=1.1 \\
\text { Load stiffness } \\
\left(\mathrm{Nm} /{ }^{\circ}\right) \\
k_{3}\end{array}$ & $J_{\text {fit }}$ \\
\hline 1 & 0.0178 & 0.102 & 0.265 & 0.032374 \\
2 & 0.020 & 0.102 & 0.265 & 0.032323 \\
3 & 0.020 & 0.111 & 0.297 & 0.101773 \\
4 & 0.0184 & 0.1026 & 0.2672 & 0.036783 \\
5 & 0.0183 & 0.1072 & 0.2558 & 0.020048 \\
6 & 0.0167 & 0.0953 & 0.2705 & 0.042441 \\
7 & 0.015 & 0.15 & 0.25 & 0.055954 \\
8 & 0.025 & 0.18 & 0.3 & 0.143948 \\
\hline
\end{tabular}

by data calculation, and a "first decomposed and then coupled" approach is employed for outputting the loading torque.

(ii) The dynamic angle of attack tracking system in the variable stiffness rudder simulation loading system can adequately simulate the NRDLT to compensate for the load torque and can better simulate the load torque in a real flight.

(iii) The solution method is relatively reasonable and can better achieve the loading to the rudder by comparing the actual load torque and simulation
TABle 3: Load stiffness for a fixed Mach number after optimization.

\begin{tabular}{lccc}
\hline$k_{1}(\mathrm{Ma}=0.4)$ & $k_{2}(\mathrm{Ma}=0.8)$ & $k_{3}(\mathrm{Ma}=1.1)$ & $J_{\text {fit }}$ \\
\hline 0.0201 & 0.0983 & 0.253 & 0.0156 \\
\hline
\end{tabular}

load torque. By optimizing the loading parameters using an optimal algorithm, excellent tracking results can be achieved, which significantly reduces the additional torque.

\section{Conflicts of Interest}

The authors declare that they have no conflicts of interests regarding the publication of this article.

\section{References}

[1] S. Holger and F. Holger, "Hardware-in-the-loop simulation with flight control actuators," in AIAA Modeling and Simulation Technologies Conference and Exhibit, San Francisco, CA, USA, 2005, American Institute of Aeronautics and Astronautics.

[2] M. Karpenko and N. Sepehri, "Hardware-in-the-loop simulator for research on fault tolerant control of electrohydraulic flight control systems," in 2006 American Control Conference, pp. 4645-4651, Minneapolis, MN, USA, 2006, IEEE.

[3] M. Karpenko and N. Sepehri, "Hardware-in-the-loop simulator for research on fault tolerant control of electrohydraulic 
actuators in a flight control application," Mechatronics, vol. 19, no. 7, pp. 1067-1077, 2009.

[4] J. J. A. Buford and T. Paone, "Using hardware-in-the-loop (HWIL) simulation to provide low-cost testing of TMD IR missile systems," in Proceedings of SPIE Volume 3368, Technologies for Synthetic Environments: Hardware-in-the-Loop Testing III, pp. 432-440, Orlando, FL, USA, 1998.

[5] S. K. Yalla, A. Kareem, S. Kabat, and F. L. Haan Jr., "Dynamic load simulator: development of a prototype," Journal of Engineering Mechanics, vol. 127, no. 12, pp. 1310-1315, 2001.

[6] S. K. Yalla and A. Kareem, "Dynamic load simulator: actuation strategies and applications," Journal of Engineering Mechanics, vol. 133, no. 8, pp. 855-863, 2007.

[7] G. Li, K. Zhao, and R. Yuan, "Study on the effect of generalized coupled stiffness in the electro-hydraulic load simulator," in Proceedings of the International Conference on Mechanical Engineering and Mechanics, pp. 1137-1141, Nanjing, China, 2005.

[8] S. Yaoxing, J. Zongxia, W. Xiaodong, and Z. Sijun, "Study on friction torque loading with an electro-hydraulic load simulator," Chinese Journal of Aeronautics, vol. 22, no. 6, pp. 691-699, 2009.

[9] Y. Nam, "QFT force loop design for the aerodynamic load simulator," IEEE Transactions on Aerospace and Electronic Systems, vol. 37, no. 4, pp. 1384-1392, 2001.

[10] S. Liu, M. Wang, K. Tian, and Y. Wang, "Research on loading simulation of DC torque motor for electrical load simulator," in 2008 3rd IEEE Conference on Industrial Electronics and Applications, pp. 1146-1150, Singapore, 2008, IEEE.

[11] N. Ullah, W. Khan, and S. Wang, "High performance direct torque control of electrical aerodynamics load simulator using fractional calculus," Acta Polytechnica Hungarica, vol. 11, pp. 59-78, 2014.

[12] N. Ullah, W. Shaoping, M. I. Khattak, and M. Shafi, "Fractional order adaptive fuzzy sliding mode controller for a position servo system subjected to aerodynamic loading and nonlinearities," Aerospace Science and Technology, vol. 43, pp. 381-387, 2015.

[13] C. Wang, Z. Jiao, S. Wu, and Y. Shang, "Nonlinear adaptive torque control of electro-hydraulic load system with external active motion disturbance," Mechatronics, vol. 24, no. 1, pp. 32-40, 2014.

[14] X. Wang, S. Wang, and B. Yao, "Adaptive robust torque control of electric load simulator with strong position coupling disturbance," International Journal of Control, Automation and Systems, vol. 11, no. 2, pp. 325-332, 2013.

[15] J. D. Schaffer, "Multiple objective optimization with vector evaluated genetic algorithms," in Psychology Press, pp. 93100, New York, NY, USA, 1985.

[16] M. Rahmati, S. R. Alavi, and S. Ziaei-Rad, "Improving the read/write performance of hard disk drives under external excitation sources based on multi-objective optimization," Microsystem Technologies, vol. 23, no. 8, pp. 33313345, 2017.

[17] X. Yao, Z. Liang, X. Song et al., "Variable stiffness simulation loading device for actuator," China Patent CN101105423, 2008.

[18] H. K. Sachs, "Criteria of design for progressive torsion-bar springs," Experimental Mechanics, vol. 7, no. 3, pp. 105109, 1967.
[19] X. Qian, R. Lin, and Y. Zhao, Missile Flight Aerodynamics, Beijing Institute of Technology Press, Beijing, 2011.

[20] D. S. Grismer, M. J. Grismer, J. M. Simon, and J. Tinapple, “An experimental investigation of factors influencing hinge moments," in 18th Applied Aerodynamics Conference, pp. 703-709, Denver, CO, USA, 2000.

[21] M. Schroeder, "Synthesis of low-peak-factor signals and binary sequences with low autocorrelation (Corresp.)," IEEE Transactions on Information Theory, vol. 16, pp. 85-89, 1970. 


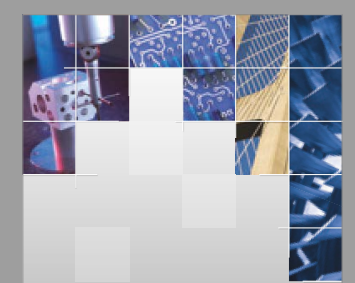

\section{Enfincering}
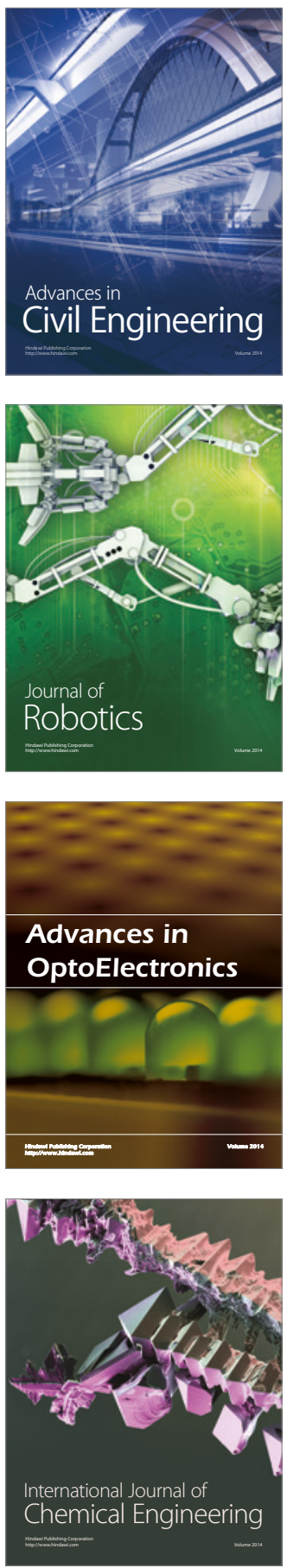

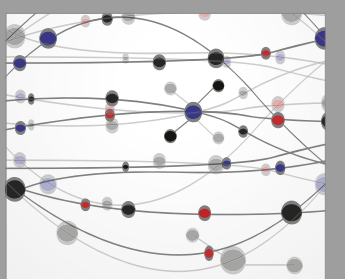

The Scientific World Journal

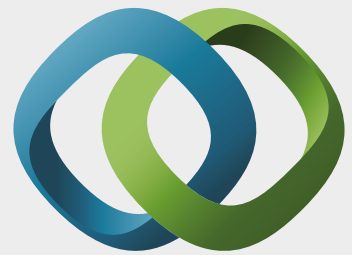

\section{Hindawi}

Submit your manuscripts at

https://www.hindawi.com
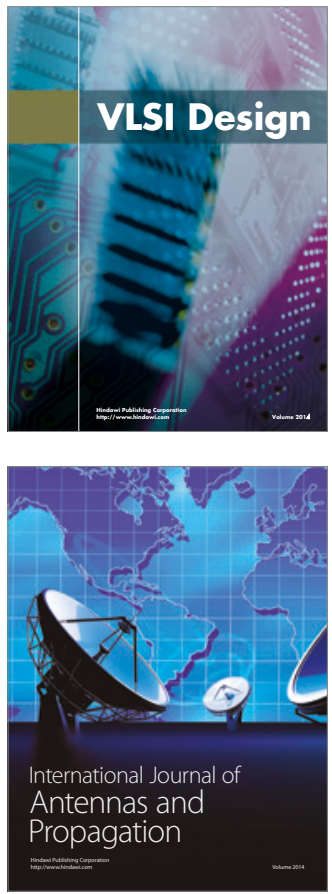

\section{Rotating}

Machinery
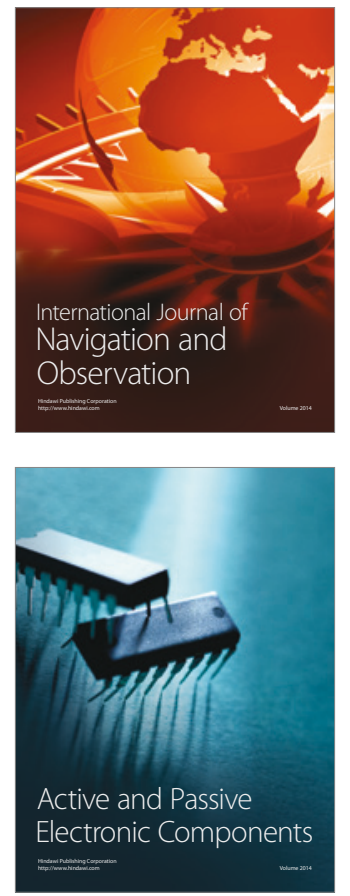
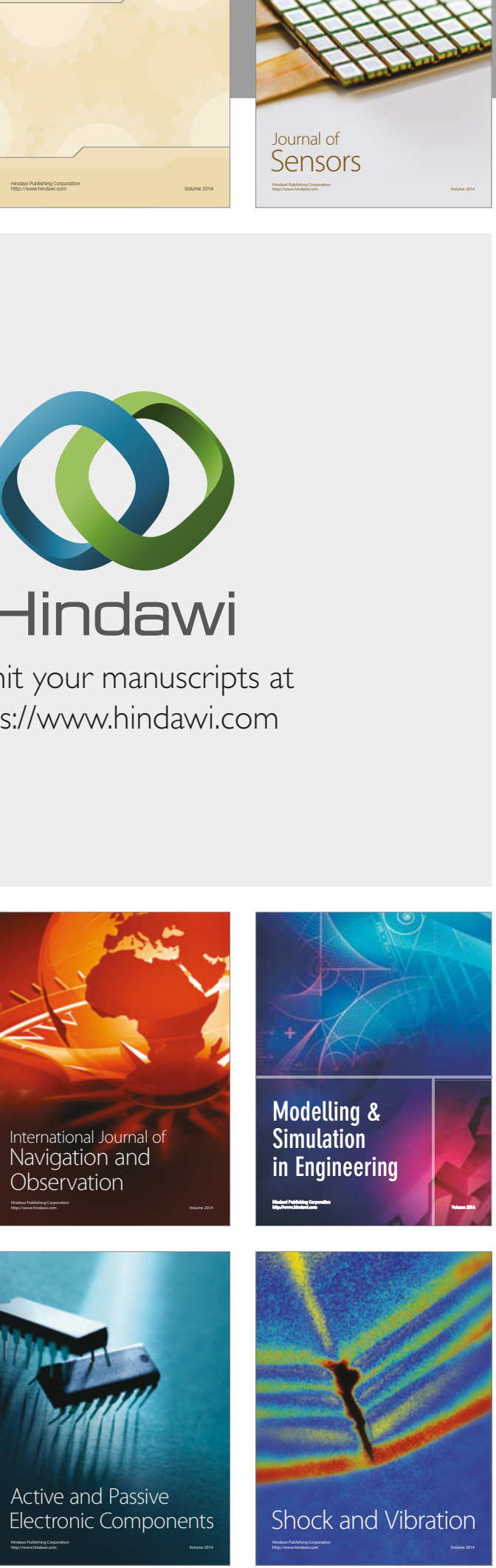
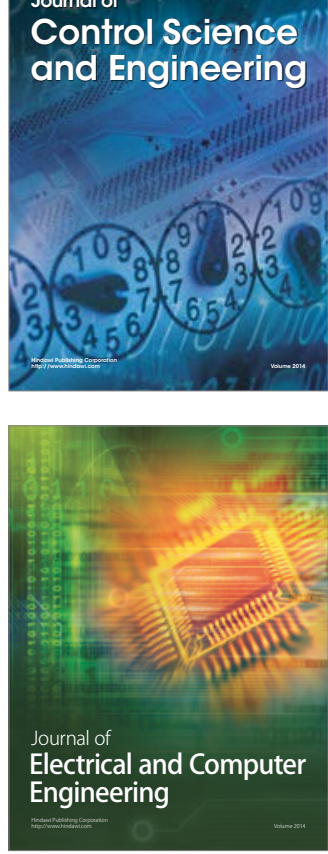

Distributed

Journal of

Control Science

and Engineering
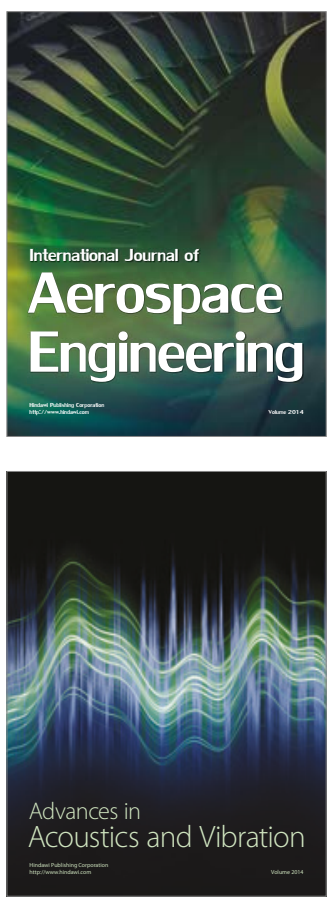

Sensor Networks 